\title{
Public Transport Reforms in Seoul: Innovations Motivated by Funding Crisis
}

John Pucher, Hyungyong Park, and Mook Han Kim, Rutgers University Jumin Song, University of Michigan

\begin{abstract}
On July 1, 2004, the Seoul Metropolitan Government introduced a wide range of reforms to its public transport system: it completely reorganized bus services, installed Bus Rapid Transit (BRT) corridors, improved coordination of bus and metro services, and fully integrated the fare structure and ticketing system between routes as well as modes. This article describes the public transport reforms in Seoul and assesses their impacts on safety, speed, costs, passenger levels, and overall customer satisfaction.
\end{abstract}

\section{Introduction}

Problems can sometimes generate solutions that yield long-term benefits. That appears to be the case in Seoul, Korea, where congestion, air pollution, traffic injuries, and increasingly serious funding shortages have forced government officials to introduce a range of innovative transport programs. Most recently, the acute funding crisis of Seoul's public transport system has prompted a complete reexamination of ways to improve service quality while keeping costs and subsidies affordable. 
This article examines the public transport reforms introduced in Seoul in July 2004 and reports on their impacts over the first few months. The reforms increased public control of bus services and reorganized the entire bus system into four divisions. The restructured bus system now includes a network of Bus Rapid Transit (BRT) routes scheduled to expand greatly in the coming years. Thanks to the reforms, bus services are now much better coordinated with each other and with Seoul's extensive metro rail system, both in their physical interchanges and in fare structures and ticketing procedures. We describe these and other complementary changes in transport policies intended to improve the performance of Seoul's public transport system. First, however, we provide a brief overview of the transport situation in Seoul, and in particular, public transport developments over the past few decades.

\section{Impacts of Population and Economic Growth on Travel Demand}

Seoul has been one of the fastest growing cities in the world. Indeed, the Greater Seoul metropolitan area quadrupled in population between 1960 and 2002 (Korea National Statistical Office 2005). With more than 22 million residents, it is now one of the world's largest and fastest growing megacities. More people obviously generate more trips and more overall travel demand. In addition, however, rapid economic growth has yet further stimulated travel. In constant, inflation-adjusted 2004 US dollars, per-capita income in South Korea rose from only \$311 in 1970 to $\$ 2,044$ in $1980, \$ 7,378$ in 1990 , and $\$ 12,531$ in 2002 (Korea National Statistical Office 2005; see Figure 1). That represents a 40 -fold increase in real per-capita income in only 32 years. Such dramatic economic growth generates large increases in both freight and passenger transport. It also makes private cars more affordable. While only a tiny percentage of Koreans owned cars in 1970 ( 2 cars per 1,000 persons), the rate of car ownership rose to 215 per 1,000 persons by 2003 (Ministry of Construction and Transportation 2003; see Figure 1).

Increased use of private cars has caused serious traffic congestion, especially on the radial arterial highways connecting the suburbs to the central city. Average roadway speeds are only $20 \mathrm{~km}$ per hour overall, and only $17 \mathrm{~km}$ per hour in the city's two central business districts (Kwon 2004; Kyung 2004). Such congested roads slowed down buses even more than cars and greatly impaired overall bus service quality. Increased car use has also caused dangerously high levels of air pollution, noise, and traffic accidents as well as excessive use of scarce land for roadways and parking facilities (Ahn and Ohn 2001; Hwang 2001; Kim and Jung 2001). 


\section{Figure 1. Increases in Car Ownership Paralleling Growth in Real Per-Capita Income in South Korea, 1970-2002 (in constant, inflation-adjusted 2004 US dollars)}

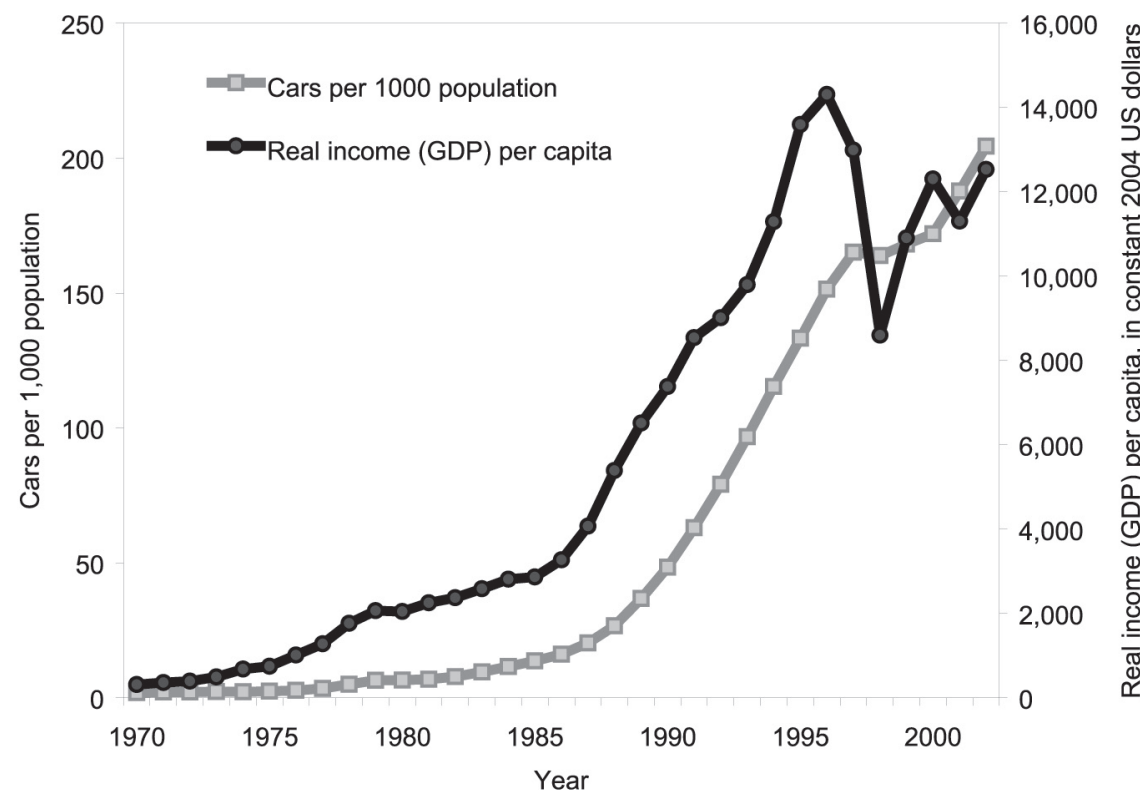

Source: Ministry of Construction and Transportation 2003; Korea National Statistical Office 2005.

\section{Reliance on Metro System to Solve Transport Problems}

Until 1974, Seoul was almost entirely dependent on bus services. Sharply rising roadway congestion, reduced bus speeds, higher passenger volumes, and longer trip distances increased the necessity for an urban rail system (Hwang 2001). Seoul constructed its first metro line in 1974. From the modest $8 \mathrm{~km}$ of that initial line, the Seoul metro rail network has expanded to a total of $487 \mathrm{~km}$ in 2004, with 13 lines and 389 stations. Indeed, the urban and suburban rail network in Greater Seoul is now one of the largest in the world and carries 8.4 million passengers per day-more than twice the daily passenger volumes on the New York subways and the London underground (Kim and Rim 2000; Seoul Metropolitan Rapid Transit Corporation 2005).

While the construction of Seoul's metro system has been an impressive accomplishment, it has come at high cost. The cumulative construction debt has now 
reached almost $\$ 6$ billion and represents 80 percent of the city's total debt. Moreover, passenger fares only cover about 75 percent of operating costs, with the remaining 25 percent subsidized through various programs by the city government. The annual operating deficit in 2003 was $\$ 634$ million. Financing both construction costs and operating deficits has put an enormous financial burden on the city. Although the central Korean government had provided fairly generous financing ( $40 \%$ to $50 \%$ ) of metro construction costs, the rising funding needs have become overwhelming. Thus, the central government has sharply restricted its funding for any new or extended metro lines-increasing the financial burden for the Seoul Metropolitan Government, which is already deeply in debt (Lee, C. 1999; Lee, J. 2003; Hwang 2002; Seoul Development Institute 2003b).

In short, both central and local government officials have been seeking more affordable ways to expand urban public transport services to meet the rising travel demands of a growing megacity. That financial pressure to seek cost-effective alternatives to metro expansion was the main impetus to the far-reaching reforms of Seoul's public transport system introduced in July 2004. As described below, the main strategy was to rely more heavily on lower-cost bus services but to greatly enhance their speed, connectivity, comfort, and overall attractiveness. Such quality improvement was desperately overdue, as described below.

\section{Bus Service in Seoul Before 2004 Reforms}

The first public bus services in Seoul began in 1953 and remained the principal mode of public transport until the mid-1990s. Bus usage rose rapidly with the growth of Seoul in the 1960s, 1970s, and early 1980s, but began a long-term decline around 1985. Bus services lost both overall market share as well as total passengers (see Figures 2 and 3). Buses had to compete with ever-expanding metro services as well as rising car ownership. Just as buses were faced with increased competition from metros and cars, bus services declined in quality due to roadway congestion that slowed down buses and made them less dependable. They also suffered from highly inefficient, uncoordinated, and dangerous operating practices of the many private bus companies who ran the services (Kim and Rim 2000; Hwang 2001).

For decades, bus services in Seoul were operated by a large number of private firms, with virtually no government control of routes, schedules, or other aspects of service. Only the fares were determined by the Seoul Metropolitan Government, which also provided increasing operating subsidies to cover growing operating 
Figure 2. Trends in Modal Shares of Total Trips in Seoul, 1980-2002 (percent of trips by each type of transport)

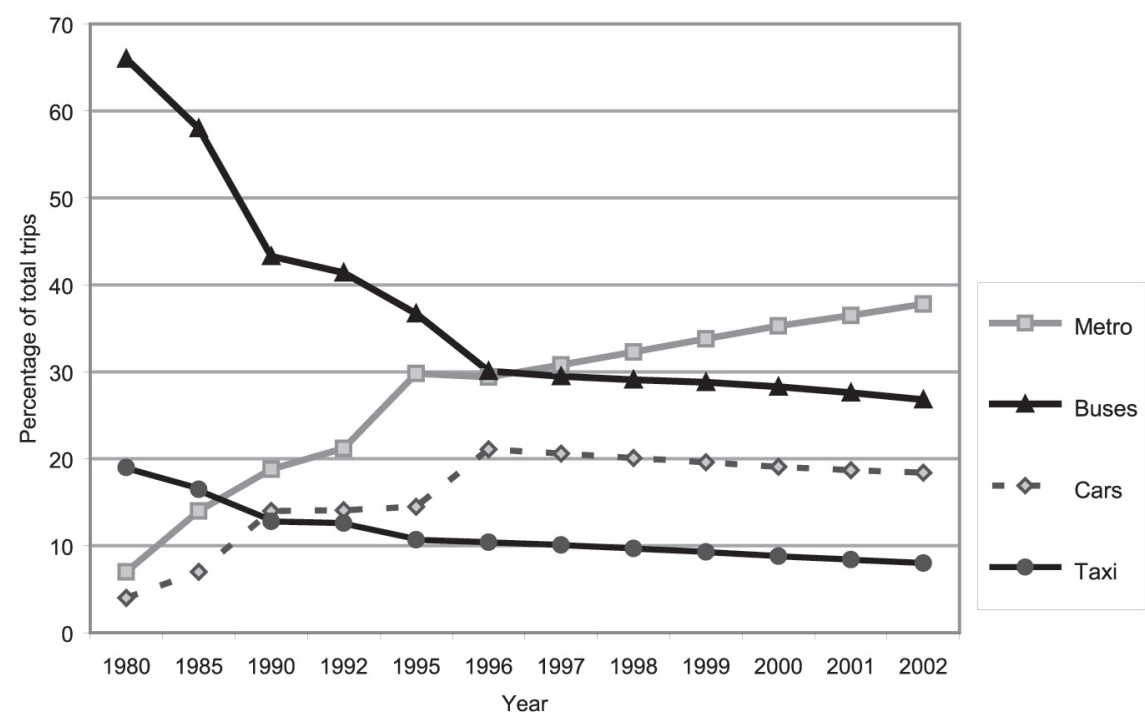

Source: Seoul Metropolitan Government 2004; Seoul Development Institute $2003 a$.

Figure 3. Trends in Bus, Metro, and Taxi Passengers in Seoul, 1980-2002 (millions of passenger trips)

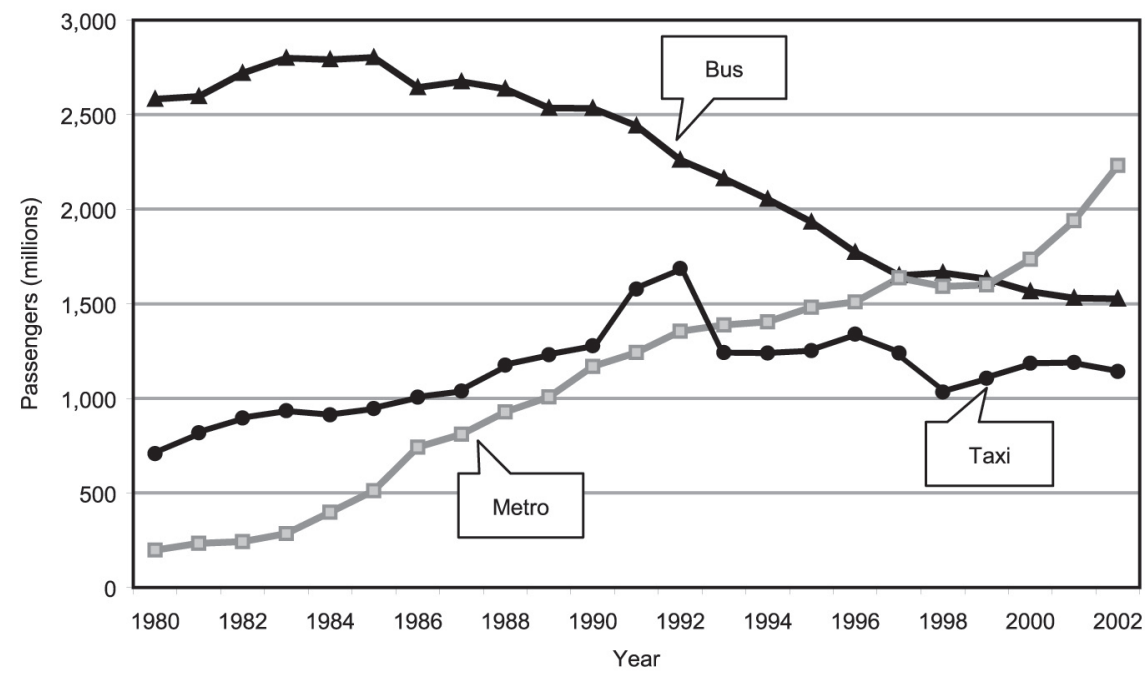

Source: Ministry of Construction and Transportation 2003. 
deficits that were causing many firms to go bankrupt or curtail the quality of their services. Each bus company operated different routes, with no competition on any particular route. Because there was no coordination among the different bus companies, many routes were highly circuitous, overlapping, and not adequately integrated with metro services and the routes of other bus companies.

Most of the private bus firms sought only to maximize profits (or minimize losses) while disregarding rider safety and comfort. Thus, an official report of the Seoul Metropolitan Government sharply criticized the private bus companies for encouraging truly outrageous bus driving behavior (Seoul Metropolitan Government 2004). To squeeze as many passengers as possible into a bus, bus drivers slammed on their brakes or suddenly and repetitively braked to jolt standing passengers further back into the bus. Bus drivers would recklessly race other buses to pick up passengers waiting at bus stops, but they deliberately avoided picking up elderly or disabled passengers to save time. In addition, bus vehicles were old, poorly maintained, and did not meet international standards. Service was dangerous, slow, uncomfortable, and unreliable.

As shown in Figure 4, the number of bus companies has fallen considerably in recent years, from 89 in 1995 to 58 in 2002 (Seoul Development Institute 2003b).

\section{Figure 4. Numbers of Bus Companies, Registered Buses, and Passengers}

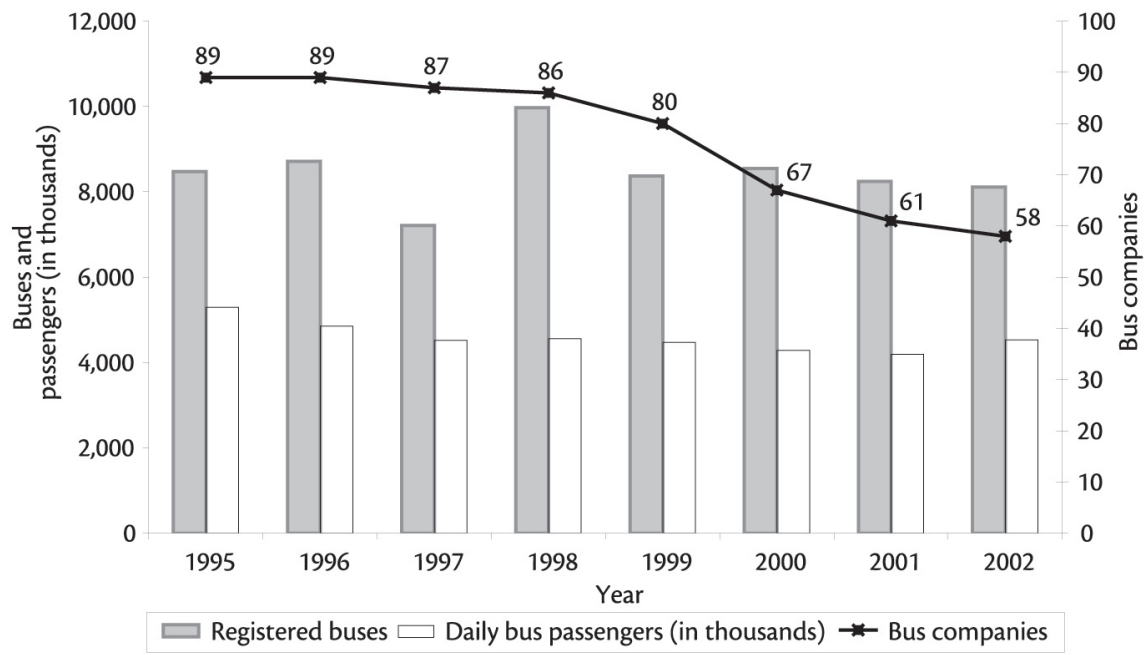

Source: Seoul Development Institute 2003b. 
To some extent, the decline was due to some firms going bankrupt. But the Seoul Metropolitan Government had also encouraged the consolidation of bus firms to eliminate duplication, reduce overhead costs, and improve coordination of services. That did not, however, solve the increasingly serious financial problems of the bus companies. As bus passengers continued to decline, there were fewer passengers per bus, less fare revenue per bus, and escalating operating deficits. For example, the average number of total daily passengers per bus fell from 1,093 in 1989 to only 494 in 2002 (Korea Transport Institute 2005).

The local government subsidy required to keep private bus services running rose from only $\$ 9$ million in 1999 to $\$ 110$ million in 2002. Although bus services covered a higher percentage of operating costs from passenger fares than metro services ( $85 \%$ vs. $75 \%$ in 2003 ), the sharply rising subsidy needs of bus services became a grave concern. The increasing subsidy burden of bus services was especially problematic on top of the enormous funding problems for metro services (Seoul Development Institute 2003a, 2003b).

The main problem, however, was sharply declining bus service quality over the past two decades, which drove away many bus passengers and encouraged more car use, congestion, and pollution. Although it did not deal with the core problem of unregulated, uncoordinated private bus firms until 2004, the Seoul Metropolitan Government made several attempts over the past two decades to speed up bus services and thus increase bus usage. To protect buses from worsening roadway congestion, the first curbside bus lanes were installed in 1984 and expanded to 89 km by 1993, 174 km by 1994, and 219 km by 2003 (Kim and Rim 2000; Seoul Metropolitan Government 2005c). The network of reserved bus lanes helped speed up bus travel somewhat, but it did not succeed in raising bus use. Clearly, more drastic changes were necessary.

\section{Planning and Implementing Bus Reforms in Seoul}

The new city mayor, Myung-Bak Lee, and the Seoul Development Institute (SDI) were crucial in researching, developing, and implementing far-reaching reforms of Seoul's public transport system. Prior to becoming mayor, Lee had been the chief executive officer of Korea's largest corporation (the Hyundai Engineering and Construction Corporation), with a reputation for being energetic, innovative, and gifted at negotiating and facilitating change (Choi 2005). When elected in June 2002, Lee promised to improve the problem-ridden public transport sys- 
tem in Seoul. He commissioned a series of comprehensive studies performed by the research division of SDI. The studies resulted in detailed reports published in December 2003 recommending coordination and modernization of the metro and bus fare structures and payment systems, better integration of bus and metro services, an expanded network of reserved bus lanes, and a complete overhaul of the organization and operation of bus services (Seoul Development Institute 2003a; 2003b). The transport specialists at SDI, led by Dr. Gyengchul Kim and Dr. Keeyeon Hwang, were the main technical advocates for these changes, while Mayor Lee and his staff provided the necessary political support.

Starting in January 2004, the mayor and staff of the Seoul Metropolitan Government conducted an intensive public relations campaign to explain through the mass media the need for the proposed reforms and the benefits that would result from them. They also announced the July 1, 2004, start date for implementation of the reforms (Seoul Metropolitan Government 2004). Since travel conditions in Seoul had been steadily deteriorating, both for motorists and transit riders, there was considerable public support for improvements, although not necessarily for the specific measures advocated by the mayor and SDI. Thus, much of the media campaign was focused on explaining and defending the specific measures to be implemented.

\section{Bus Services in Seoul After 2004 Reforms}

July 1, 2004, marks a milestone in metropolitan Seoul's transport policies, especially those affecting bus services. Perhaps most important, the Seoul Metropolitan Government greatly increased its control over bus routes, schedules, fares, and overall system design. It introduced what it calls a "semi-public operation system" that retains private bus firms but leaves route, schedule, and fare decisions to the Seoul Metropolitan Government. Moreover, it now reimburses bus firms on the basis of vehicle $\mathrm{km}$ of service instead of passenger trips, which should increase incentives to improve service quality and reduce incentives for speeding, reckless driving, and discriminating against elderly and disabled passengers (Eum 2005; Kim, G. 2004; Seoul Development Institute 2003a, b; Seoul Metropolitan Government 2004).

One of the first major changes was an entire redesign of the bus route network to better structure and integrate more than 400 different bus routes. All bus services are now grouped into four types, with buses color-coded to help passengers dis- 
tinguish between them. Blue buses are long-distance express buses that connect outlying suburbs with each other and with the city center. Red buses are long-distance express buses that connect the satellite cities (planned new towns) with the city center. Green buses provide local services throughout the metropolitan area to feed metro stations and express bus stops. Yellow buses provide local services within the city center (Kwon 2004; Kyung 2004).

To coordinate bus services on a truly comprehensive, systemwide basis, the Seoul Metropolitan Government set up a new Bus Management System (BMS) using advanced intelligent transport system (ITS) technology. Global positioning system (GPS) terminals located in every bus now permit a central bus control center to monitor all bus locations and speeds, adjust the number of buses assigned to any given route, communicate with bus drivers, and provide real-time information to passengers waiting at bus stops or checking bus schedules on the Internet (Seoul Development Institute 2003a). The new BMS facilitates more dependable, on-time bus service while also providing better, real-time information for passengers. It also helps optimize service distribution by adjusting bus assignments and scheduling to conform better to the different travel demands on different parts of the extensive bus network.

In addition to the complete redesign of the route network, the system of dedicated bus lanes was expanded and upgraded. The length of curbside bus lanes was increased from $219 \mathrm{~km}$ to $294 \mathrm{~km}$, with more expansions planned. Most significant, however, is the development of a true BRT network with dedicated bus median lanes, high-quality median bus stops, real-time information for passengers and system operators, and new, state-of-the-art buses. By February 2005, there were already $36 \mathrm{~km}$ BRT services spanning 4 different corridors. During 2005 and 2006, there will be an additional $62 \mathrm{~km}$ of BRT over 7 more corridors. BRT route expansion is likely to continue after that. Seoul's BRT services benefit from an increasing number of new buses. By 2006, there will be more than 300 low-floor buses, mostly running on CNG (compressed natural gas). Of those, about 20 will be articulated buses. Eventually, all the blue and red express buses will be CNG and low-floor, and all red buses will also be articulated. With level boarding platforms at BRT stops, getting on and off express buses will be easier, faster, and safer. The Seoul Metropolitan Government now views BRT as a much cheaper and quicker way to provide express public transport services than metro expansion, which can take many years to construct and requires much more capital investment (Seoul Metropolitan Government 2004). 
Journal of Public Transportation, Vol. 8, No. 5, 2005

Figure 5. Bus Median Lanes

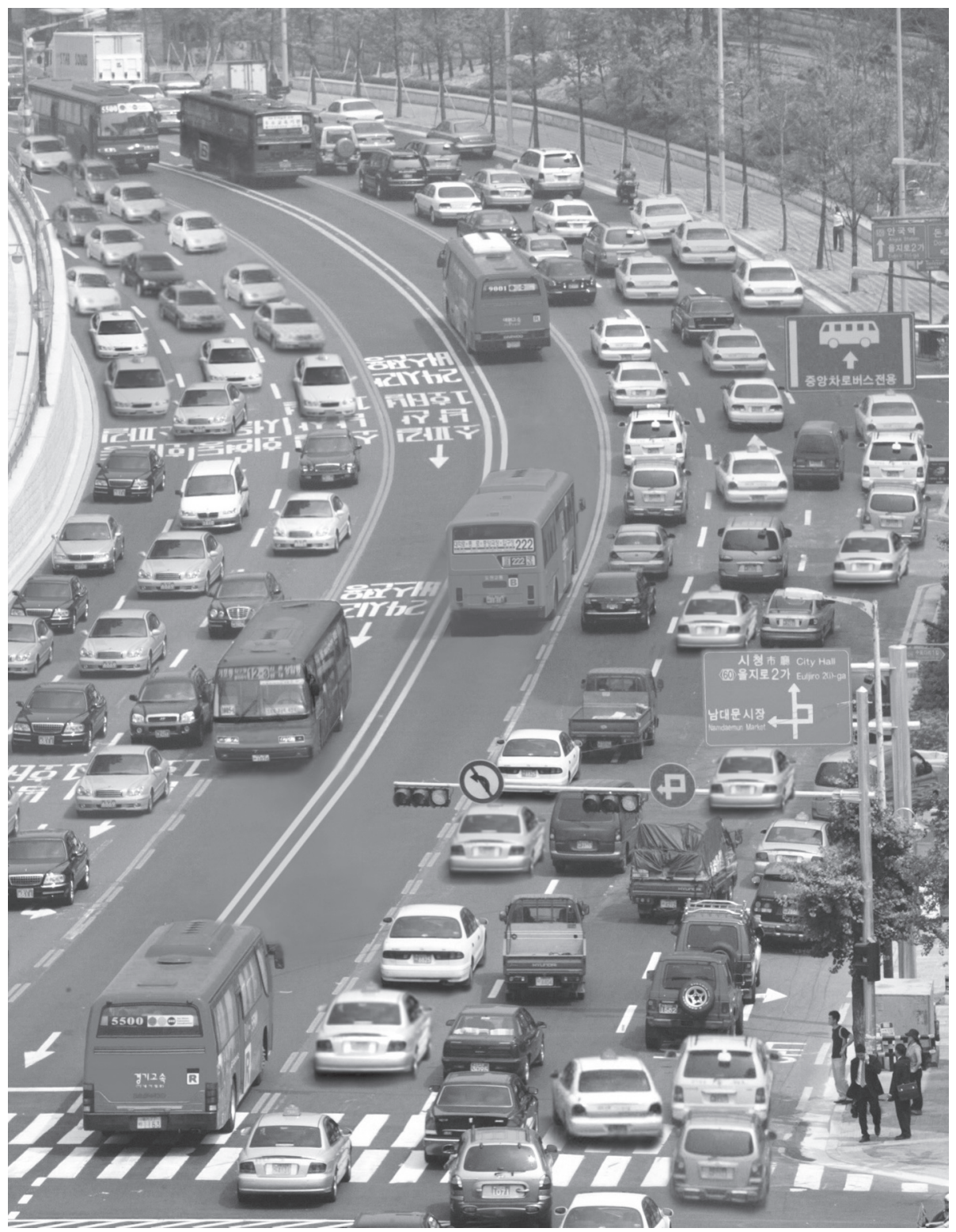


Nevertheless, the extensive urban and suburban rail lines in Seoul remain the backbone of Seoul's public transport system. Thus, it is crucial to better integrate both local and express bus services with the metro. Bus routes and stops have already been relocated to facilitate short and easy transfers between the bus and metro. To further facilitate bus-metro transfers, the city is now constructing 22 major transfer centers that will offer passengers convenient, sheltered bus stations providing real-time information about metro as well as bus services.

In addition to these major service improvements, the Seoul Metropolitan Government introduced a unified, coordinated fare structure that integrates both bus and rail services (Seoul Development Institute 2003b). Fares are now based only on distance traveled, with free transfers permitted between bus lines as well as between metro and bus. Although the overall fare level was increased, the distance zones that had previously only applied to metro fares were enlarged to permit longer trips without the distance surcharge. Equally important, there is now a multipurpose, stored-value smart card (called "T-Money") that can be used for all bus and rail services, greatly enhancing ease of payment for the traveler. Also, for the first time there are now monthly commutation tickets that offer discounts to regular travelers.

\section{Impacts of the Reforms}

In the weeks immediately after implementation of the July 2004 reforms, there was great disruption, confusion, and dissatisfaction among passengers. As shown in Figure 6, more than half of all passengers surveyed in early July were very dissatisfied with the changes. Roughly 70 percent said they were dissatisfied with the new fare structure, and about 60 percent were confused about the new bus routes. The only aspect of bus services that appears to have immediately improved was the performance of bus drivers, since passenger satisfaction with driver behavior almost immediately improved on July 1 , when the bus reforms came into effect. As very clearly shown in Figure 6, customer satisfaction dramatically improved in subsequent weeks and months, as passengers were better informed about the new bus routes and schedules, and technical problems were worked out with the new smart card. Overall passenger dissatisfaction fell from a high of 56 percent on July 8 to 44 percent on July 29 and only 13 percent on October 28 . Thus, within four months of the thorough reform of bus services and fares, almost 90 percent of customers expressed general satisfaction (Seoul Development Institute 2004). 


\section{Figure 6. Decreasing Customer Dissatisfaction with Seoul Bus Reforms over the Four-Month Period after Their Introduction, from July 1, 2004}

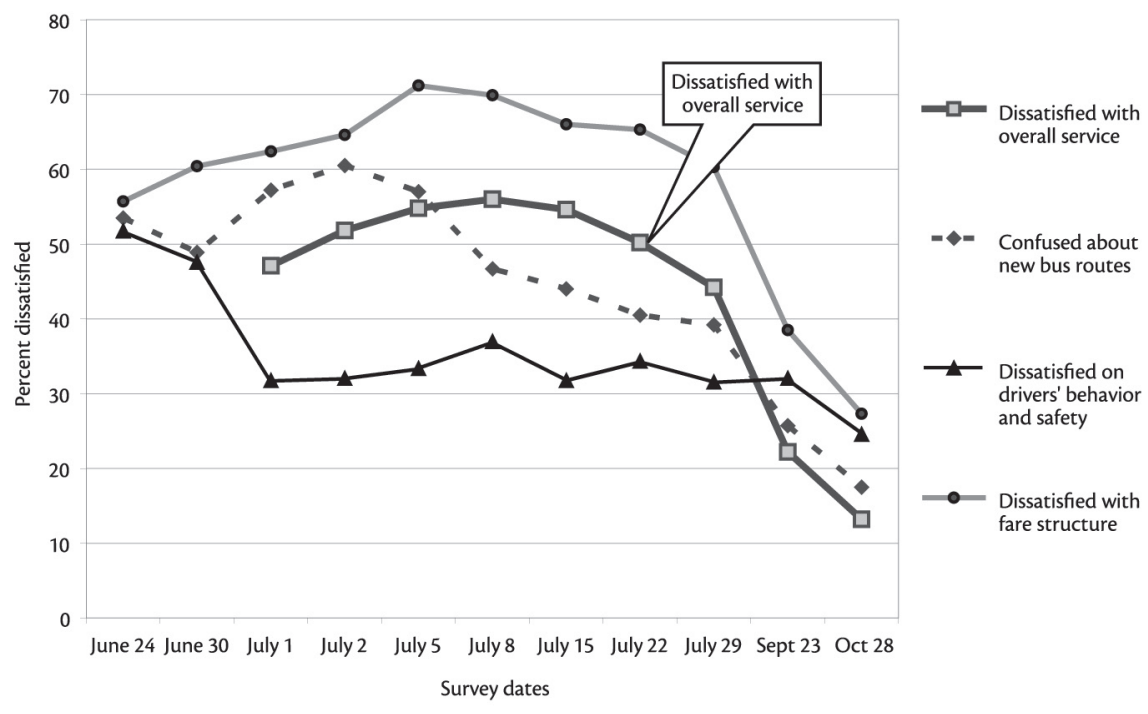

Source: Seoul Development Institute 2004.

One reason for the rising customer satisfaction might be the dramatic increase in bus speeds on BRT corridors (see Figure 7). Between June 2004 and December 2004, average bus speeds doubled in the Dobong-Mia BRT corridor (from 11 to 22 $\mathrm{km} / \mathrm{hr}$ ) and increased by 64 percent and 33 percent in the other two BRT corridors (Seoul Development Institute 2004). Even more impressive, average bus speeds are now only slightly lower than average car speeds. Car speeds have also increased in BRT corridors, since the removal of buses from the general traffic has reduced the disruption caused by buses zigzagging across lanes to and from the curbs to pick up and drop off passengers. The greatest improvement in speed, however, has been for buses, and on average, each BRT median lane now carries six times more passengers than other lanes in the same corridor.

Bus speeds are likely to rise even further with implementation of Transit Signal Priority (TSP), which will facilitate bus turns and reduce waiting times for buses crossing intersections. TSP in Seoul was delayed while waiting for installation and full functioning of the citywide Transport Operation and Information Service (TOPIS). Inaugurated in July 2005, this fully computerized system coordinates roadway traffic as well as public transit vehicles, thus permitting the optimization of traffic signals to speed up buses (Korea Times 2005). 


\section{Figure 7. Average Bus and Car Speed Before and After Implementation of Exclusive Median Bus Lanes}

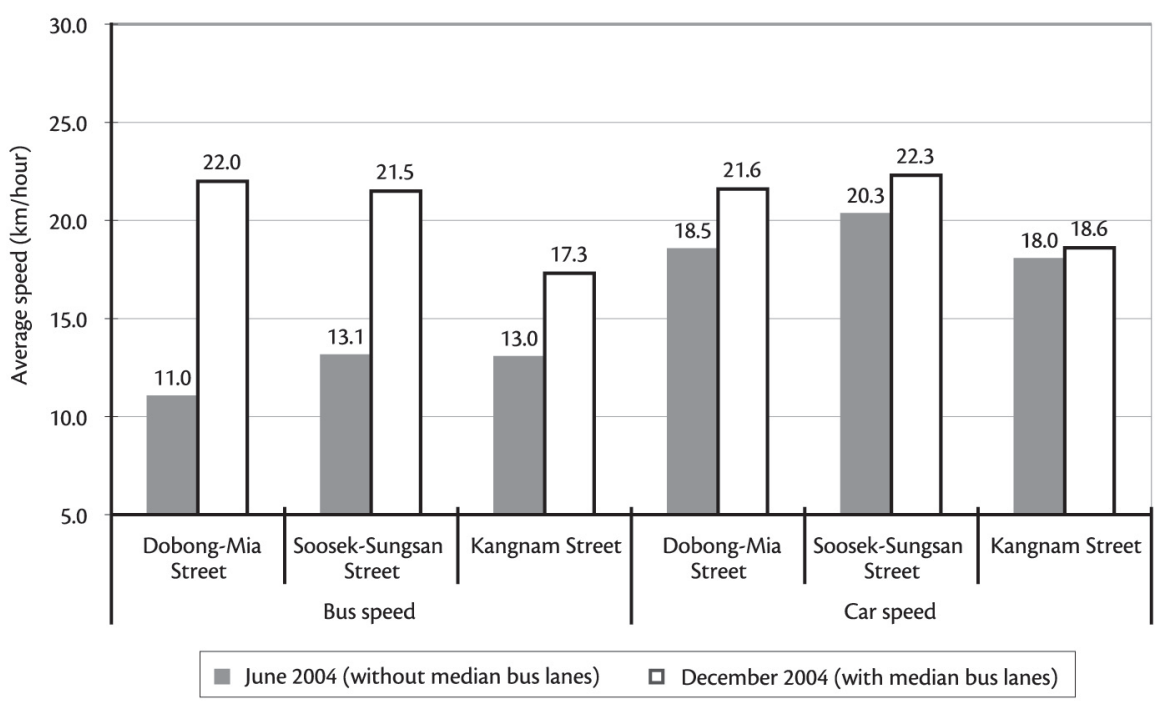

Note: 7-9 A.M., toward city center.

Source: Seoul Metropolitan Government 2005a.

Another benefit of the bus reforms has been an impressive decline in bus-related accidents and personal injuries. As shown in Figure 8, both the number of bus accidents and the number of personal injuries in bus accidents have fallen by about a third since implementation of the bus reforms. The improvement in bus safety may be attributed to better driver performance as well as greater right-of-way separation for buses in the BRT corridors.

Rising bus passenger levels are perhaps the best indicator of the success of the reforms (see Figure 9). Only in the first month of the reform (July) was the number of bus passengers less than the same month a year earlier (in July 2003) prior to the reforms. That was due to widespread disruption, confusion, and malfunctions as the new service and fare systems were introduced. By comparison, daily bus ridership increased by 406,000 passengers per day between September 2003 and September 2004 (+9\%) and by 705,000 passengers per day between March 2003 and March 2004 (+14\%) (Seoul Metropolitan Government 2005b). Metro ridership remained roughly constant before and after the bus reforms, as shown in Figure 9. 
Figure 8. Decline in Monthly Bus Accidents and Injuries in Seoul, 2003 to 2005

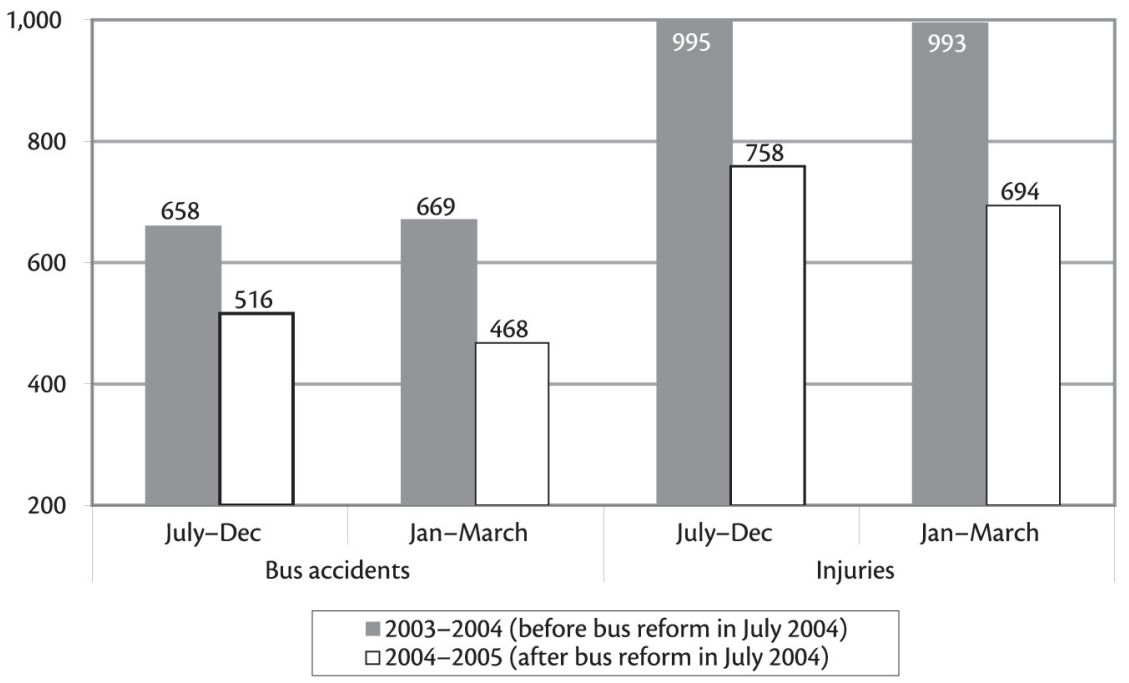

Source: Seoul Metropolitan Government 2005a.

\section{Figure 9. Trends in Average Daily Bus and Metro Passengers \\ Before and After July 2004 Reforms (in millions)}

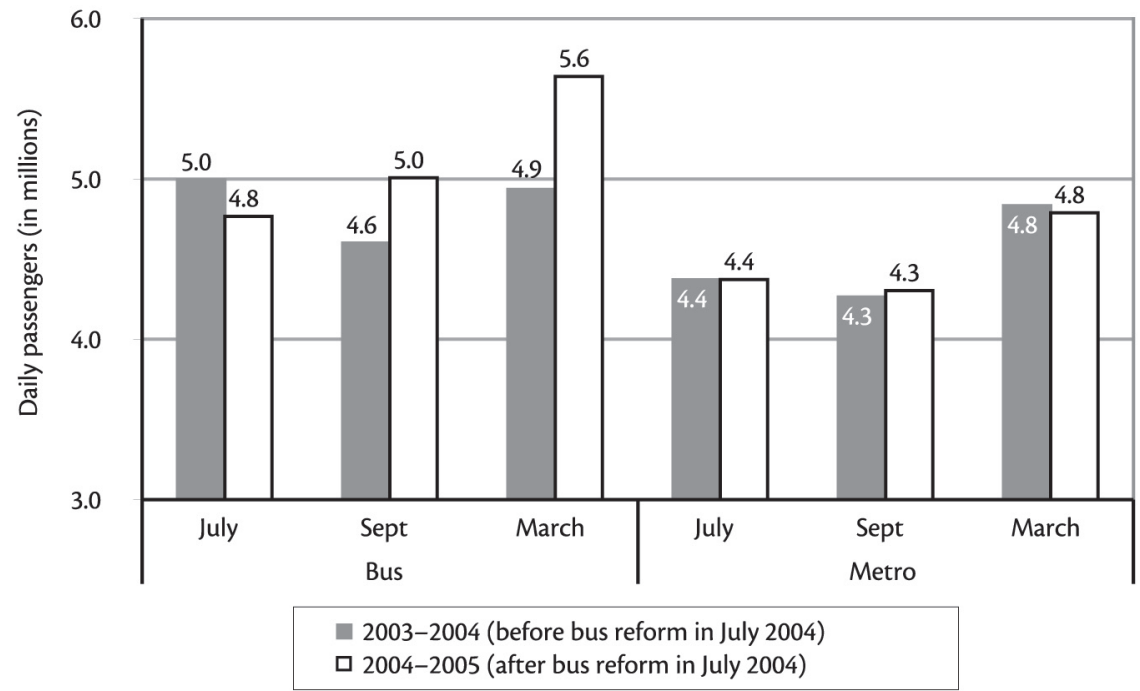

Source: Seoul Metropolitan Government 2005a. 
The new T-money fare collection system permits far more up-to-date monitoring of passenger levels than ever before. Figure 10 shows average daily bus passenger levels reported on a week-by-week basis, with only a few days lag, and accessible on Seoul's public transport information website ( $h t t p: / / b u s . g o . k r)$. With the exception of two major holiday periods, when many Seoul residents are on vacation, the general trend of bus ridership is definitely upward. From early January to late May 2005 , the number of bus passengers rose by almost a million passengers a day-an increase of about one fourth (Seoul Metropolitan Government 2005a).

The reforms appear to have considerably increased overall service quality, but they have failed to curtail subsidy needs. Indeed, as part of the bus system reorganization, the Seoul Metropolitan Government signed a contractual agreement with the private bus firms to cover their full operating deficits. This action has required an operating subsidy of $\$ 135$ million in the six-month period after the reforms,

\section{Figure 10. Trends in Average Daily Bus Passengers in Seoul, Week-by-Week, from Sept. 2004 to July 2005 (in millions)}

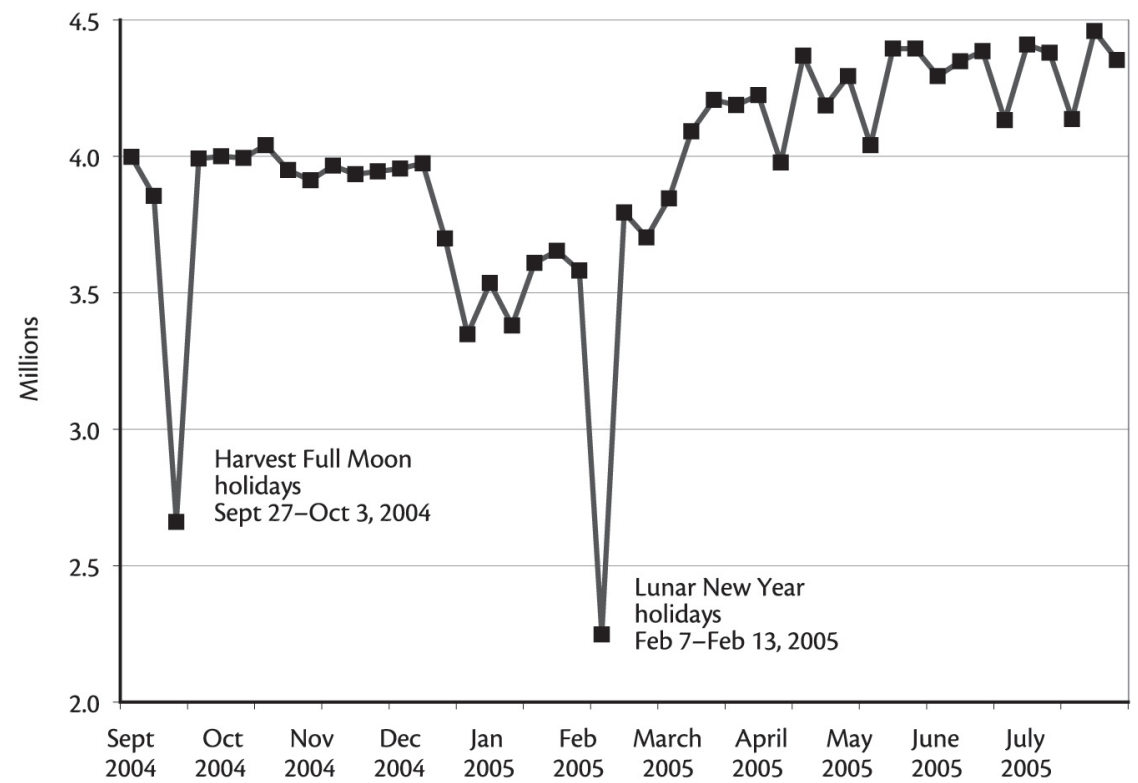

Source: Seoul Metropolitan Government 2005b. 
which would entail an annual operating subsidy of almost $\$ 270$ million just for bus services-almost three times as much as the annual bus subsidy prior to reforms (Kim, K. 2005).

The sharp increase in bus subsidy needs is alarming, but must be considered in light of substantial increases in the overall quality of bus services, including new buses, new shelters at bus stops, and the installation of BRT services to augment the existing bus services. Moreover, the alternative would be expanding the much more expensive metro services, which would have required even larger subsidy increases.

Most of the planned expansion of Seoul's public transport system involves BRT, since it is by far the cheapest form of express transit service. Almost everywhere in the world where BRT has been implemented, it has been only a fraction of the cost of rail transit. The U.S. General Accounting Office (2001), for example, estimated the average construction cost of full-scale BRT (as in Seoul) at about $\$ 9.4$ million per $\mathrm{km}$, compared to $\$ 23$ million per $\mathrm{km}$ for Light Rail Transit (LRT) and $\$ 87$ million per $\mathrm{km}$ for metro rail.

Moreover, BRT can be implemented much more quickly than any form of rail transit, and is also far more flexible in terms of adapting to future changes in travel patterns. It has the added benefit of eliminating many transfers, since buses can run express on the high-speed median lanes and then branch off into lower density areas to provide local feeder and distribution service to outlying neighborhoods.

\section{Light Rail Transit Plans}

Seoul, like many Korean cities, has tentative plans to build several new LRT lines. While LRT costs much more than BRT, it cost less than building or extending metro lines. Park and Han (2003), for example, estimate that the cost of constructing new LRT lines ranges from $\$ 20$ million to $\$ 50$ million per $\mathrm{km}$, compared to a range of $\$ 80$ million to $\$ 100$ million for metro lines. For LRT lines that are fully underground, the cost difference is much less, however. For example, the LRT line currently being constructed in the southern Korean port city of Busan is costing $\$ 63$ million per $\mathrm{km}$. It is the only LRT line in Korea already under construction. The proposed underground LRT line in northeastern Seoul would cost $\$ 65$ million per km, just about the same as in Busan (Kang 2005). Both of these LRT lines are cheaper substitutes for previously planned metro extensions. The Seoul Metropolitan Government estimates that the full-scale metro version of the northeastern 
rail line would cost $\$ 107$ million per $\mathrm{km}$, almost twice as much as the LRT version of the same line, and more than 10 times as expensive as the per-km cost of BRT.

The planned LRT line in northeastern Seoul is only one of many lines that have been proposed for Greater Seoul. Not a single line has yet been started, however. The limiting factor has been insufficient financing. In virtually every proposed new rail project, local and central government officials are hoping for private investors to finance at least half the total construction costs. So far, however, private investors have not come forth with the necessary funding. If they eventually do, the Korean central government (through the Ministry of Construction and Transportation) and Seoul Metropolitan Government would each bear about a fourth of the construction cost, provided they both give their official approval of each specific project.

\section{Conclusions}

The path-breaking reforms of July 2004 completely restructured bus services in Seoul and increased public control over routes, schedules, and other aspects of service. In addition, they integrated bus routes, schedules, and fares with the metro system, thus providing a far superior overall public transport system. Central to the reforms was the introduction of an entirely new system of BRT routes, with fully separate median lanes for express buses.

In the first month of the reforms, there was tremendous disruption, confusion, public discontent, and political uproar. Clearly, more time was needed to ensure a smooth transition to the completely new bus routes, fare structure, and fare payment system. In particular, there should have been a trial period to test new technologies on a selective basis instead of immediately adopting them systemwide. Moreover, the widespread confusion among transit riders indicates that more time and effort was needed to distribute the appropriate information to the public before implementing the reforms.

In spite of these temporary, transitional problems, the reforms appear to have become a huge success. Already by October 2004, almost 90 percent of Seoul residents expressed general satisfaction with the restructured bus services and new fare system. Average bus speeds increased by 33 percent to 100 percent in the BRT corridors. Total bus accidents and injuries on all routes combined (express and local) have fallen by about a third. Month-by-month comparisons of total bus use 
before and after the reforms indicate more than 700,000 additional bus passengers a day, while metro use has remained just about constant.

The looming financial crisis of Seoul's public transport system was the driving force behind the drastic reforms of July 2004. Shortage of public funds continues to force Seoul transport planners and public officials to seek solutions that are as cost-effective as possible, providing the best possible service to the most passengers at the lowest possible fares and government subsidies. BRT appears to fit those requirements better than metro expansions or new LRT lines.

While Seoul can boast a fast, extensive metro system, it cannot afford to expand it much further, since metro construction debts already greatly burden the Seoul Metropolitan Government's finances. The extension and continual upgrading of BRT is likely to be the most cost-effective approach to providing the additional public transport services needed throughout the greater metropolitan area. Studies of existing BRT systems around the world demonstrate that they can provide excellent express service at a fraction of the cost of new metro construction. The experience with BRT in Seoul so far has also been a resounding success. Indeed, the International Association of Public Transport recently honored Mayor Lee and the Seoul Metropolitan Government with a special award for "extraordinary success at implementing so many transit reforms in such a short period of time, integrating innovative technologies with new infrastructure" (Kim, T. 2005).

\section{Acknowledgments}

The authors would like to thank the following for their generous assistance and extensive contributions to our research: Dr. Gyengchul Kim, Dr. Keeyeon Hwang, and Miyoung Oh of the Seoul Development Institute; Jung-Hee Ahn of the Ministry of Construction and Transportation; Kyung-Joo Choi and Young-Wan La of the Seoul Metropolitan Government; and Dr. Ju Taek Oh and Dr. Sang-Gyu Hwang of the Korea Transport Institute. 


\section{References}

Ahn, K., and Y. Ohn. 2001. Metropolitan growth management policies in Seoul: A critical review. In Kwon, W., and K. Kim, eds., Urban Management in Seoul: Policy Issues and Responses. Seoul, South Korea: Seoul Development Institute, 49-72.

Choi, S. 2005. Seoul's mayor shows his green streak. International Herald Tribune, July. 25, 2005. Newspaper, Accessible at: http://www.iht.com/articles/2005/07/24/news/mayor11.php.

Eum, S. 2005. The Seoul bus system reform project. Metropolis award application document. Seoul, South Korea: Seoul Metropolitan Government.

Hwang, K. 2001. Transportation policy in Seoul. In Kwon, W., and K. Kim, eds., Urban Management in Seoul: Policy Issues and Responses. Seoul, South Korea: Seoul Development Institute, 107-124.

Hwang, S. 2002. Policy direction and strategies for debt reduction of the Seoul metropolitan subway system. Prepared for the 21st Ahnmin Transportation Forum. Seoul, South Korea: The Ahnmin Institution.

Kang, B. 2005. Passing through 13 stations including Mia, Seoul...Building an underground light-rail transit. Joongang Daily, Jan. 26, 2005. Accessible at: http://news.joins.com/society/200501/26/200501261759141801300037003710. html.

Kim, G. 2004. New transport system in Seoul. South Korea: Seoul Development Institute.

Kim, G., and J. Rim. 2000. Seoul's urban transportation policy and rail transit plan: Present and future. Japan Railway \& Transport Review 25: 25-31.

Kim, K. 2005. Required operating subsidy of $\$ 135$ million in the 6-month period after the reforms. Pressian, May. 7, 2005. Accessible at: http://www.pressian. com/Scripts/section/article.asp?article_num $=20050506160224 \& s \_m e n u=$.

Kim, M., and H. Jung. 2001. Spatial patterns and policy issues of the Seoul metropolitan region. In Kwon, W., and K. Kim, eds., Urban Management in Seoul: Policy Issues and Responses. Seoul, South Korea: Seoul Development Institute, 73-106. 
Journal of Public Transportation, Vol. 8, No. 5, 2005

Kim, T. 2005. Seoul's transport system gains recognition. Korea Times. July. 8, 2005. Accessible at: http://times.hankooki.com/lpage/200507/ kt2005070818591168040.htm.

Korea National Statistical Office. 2005. Korean statistical information system. Daejeon, South Korea: National Statistical Office. Accessible at: http://kosis. nso.go.kr/.

Korea Times. 2005. Real-time transportation information. Korea Times. July 6, 2005. Accessible at: http://times.hankooki.com/lpage/nation/200507/ kt2005070621180912000.htm.

Korea Transport Institute (KOTI). 2005. Korea transport database. Goyang, South Korea: KOTI. Accessible at: http://www.ktdb.go.kr/.

Kwon, Y. 2004. New direction for the sustainable urban transportation in Korea. Prepared for the International Workshop on the Asian Approach toward Sustainable Urban Regeneration. Tokyo, Japan: Center for Sustainable Urban Regeneration, University of Tokyo.

Kyung, S. 2004. Toward a sustainable transportation system: New transportation policies in Seoul. Seoul, South Korea: Department of Civil Engineering, Seoul National University.

Lee, C. 1999. Re-establishment of urban rail transit plan and its eligibility criteria. Goyang, South Korea: Korea Transport Institute.

Lee, J. 2003. A study on legislation for mass transit development. Goyang, South Korea: Korea Transport Institute.

Ministry of Construction and Transportation. 2003. Statistics yearbook 2003. Gwacheon, South Korea: Ministry of Construction and Transportation. Accessible at: http://www.moct.go.kr/EngHome/DataCenter/Statistic/Statistic01.htm.

Park, K., and K. Han. 2003. The study for state of construction and improvement policy of advanced transit system of Korea. Korean Society for Railway 2003 Fall Conference Proceedings. Seoul, South Korea: Korean Society for Railway. Accessible at: http://library.krri.re.kr/03_own/sub_main03.html.

Seoul Development Institute. 2003a. Guidelines for implementation of the transportation system reform in Seoul: Bus operation system. Seoul, South Korea: Seoul Development Institute. 
Seoul Development Institute. 2003b. Guidelines for implementation of the transportation system reform in Seoul: Policy for public transportation fare. Seoul, South Korea: Seoul Development Institute.

Seoul Development Institute. 2004. Monitoring bus service systems: For Seoul bus system reform programs. Seoul, South Korea: Seoul Development Institute.

Seoul Metropolitan Government. 2004. Understanding the bus system reform in Seoul. Seoul, South Korea: Transportation Bureau, Seoul Metropolitan Government.

Seoul Metropolitan Government. 2005a. Average daily bus passengers by week. Seoul, South Korea: Seoul Metropolitan Government. Accessible at: $h t t p: / /$ www.t-money.co.kr/jsp/pub/bus/buspassenger.jsp.

Seoul Metropolitan Government. 2005b. Performance analysis of public transportation system reform, March 2005. Seoul, South Korea: Seoul Metropolitan Government.

Seoul Metropolitan Government. 2005c. Transport statistics. Seoul, South Korea: Transportation Bureau, Seoul Metropolitan Government. Accessible at: http://www.seoul.go.kr/.

Seoul Metropolitan Rapid Transit Corporation. 2005. Origin and development of the Seoul metropolitan subway system. Seoul, South Korea: Seoul Metropolitan Rapid Transit Corporation. Accessible at: http://www.smrt.co.kr/english/ smrt/state_smsc.jsp? $m 1=1 \& m 2=4$.

U.S. General Accounting Office. 2001. Bus rapid transit shows promise. Washington, DC: General Accounting Office.

\section{About the Authors}

JOHN PUCHeR (pucher@rci.rutgers.edu) is professor of planning and public policy at Rutgers University in New Brunswick, New Jersey. He specializes in comparative research on transport systems, travel behavior, and public policies in the United States, Canada, and Europe. During the 2005-2006 academic year, Dr. Pucher is a visiting professor at the Institute of Transport Studies of the University of Sydney, Australia. 
HyUngyong PARK (hypark@eden.rutgers.edu) is a Ph.D. candidate in planning and public policy at Rutgers University. His Ph.D. dissertation uses geographic information systems to analyze locational differences in housing prices.

Mook HAN KıM (yohanna@eden.rutgers.edu) is a Ph.D. candidate in planning and public policy at Rutgers University. His dissertation topic is sustainable, ecoindustrial development.

JUMIN SONG (zoomin@umich.edu) is a doctoral student in urban and regional planning at the University of Michigan. His dissertation examines the interrelationships of transportation investment, development patterns, and travel demand. 